\title{
Feasibility Evaluation of a Long-Life Asphalt Pavement for Steel Bridge Deck
}

\author{
Leilei Chen $\mathbb{D}^{1}{ }^{1}$ Zhendong Qian, ${ }^{1}$ Daoxie Chen, ${ }^{1}$ and Ya Wei ${ }^{2}$ \\ ${ }^{1}$ Intelligent Transportation System Research Center, Southeast University, Nanjing 211189, China \\ ${ }^{2}$ Department of Civil Engineering, Tsinghua University, Beijing 100084, China \\ Correspondence should be addressed to Leilei Chen; chenleilei@seu.edu.cn
}

Received 25 October 2019; Revised 25 May 2020; Accepted 3 June 2020; Published 28 June 2020

Academic Editor: Yuqing Zhang

Copyright (c) 2020 Leilei Chen et al. This is an open access article distributed under the Creative Commons Attribution License, which permits unrestricted use, distribution, and reproduction in any medium, provided the original work is properly cited.

In order to extend the service life of the steel bridge deck pavement, a long-life steel bridge deck pavement (LLSBDP) was put forward referring to the concept of long-life asphalt pavement. First, the requirements of the LLSBDP were given, based on which, an LLSBDP structure "EAC + SMA" was proposed. Second, a numerical analysis was performed to evaluate the stress status of the "EAC + SMA" structure. Third, an experimental study was conducted to assess the performance of the pavement material and the pavement structure. Meanwhile, for comparison, the performances of traditional steel bridge deck pavement structure "EAC + EAC" were also studied in the numerical and experimental program. The results showed that, with periodical rehabilitation or reconstruction of the SMA surface layer, the EAC base layer can last for a long life without structural distresses. The proposed structure can meet the requirements of LLSBDP and can be used to extend the service life of the steel bridge deck pavement.

\section{Introduction}

Steel bridge deck pavement (SBDP) is an important layer paved on steel bridges and used to protect the steel bridge deck as well as providing service to the vehicle [1]. The design life of the SBDP is usually around 15 years, while the design life of the steel bridges is 100-120 years. During the service period of the bridges, the SBDP should be rebuilt for several times. In fact, bridges served as the throat channels of the roadway net; the traffic loads are much greater than normal roads. Besides, for the special support structures, the stress states of the SBDP are more complicated as well. For the reasons above, the actual average service life of the SBDP is less than 10 years. In this case, extending service life of the SBDP receives lots of attentions in recent years.

SBDP has been used for decades, and it was designed as an ordinary asphalt pavement at first. With the developments of the transportation and the bridge construction technique, the steel bridge spans and the traffic loads were increased significantly. The traditional SBDP could not meet the requirements and its service life decreases sharply. In this case, many researches have been conducted to make the stress state of the SBDP clear [2-4], to find the suitable paving material [5-7], and to establish the design method of the SBDP as well [8]. Till the first decade of the 21 century, 3 materials were selected as the most suitable pavement material: SMA, guss asphalt (GA), and epoxy asphalt concrete (EAC). Among these 3 materials, EAC has been proved to be an excellent material for its high modulus and fatigue life [9]. Thus, it has been extensively used as the pavement material for steel bridge deck all over the world.

EAC is an asphalt concrete bonded with epoxy asphalt, which is modified with epoxy resin. Unlike most thermoplastic asphalt concrete, EAC is a thermosetting material. As an irreversibly cure material, thermosetting material can be cured through heating and chemical reactions, and it cannot be melted or reshaped after being cured. This thermosetting character has brought the EAC some special properties, such as large strength and good fatigue resistance. Investigation shows that over $60 \%$ long-span steel bridges across the Yangtze River in China were paved using EAC, and the average service lives of these SBDP were larger than other 
bridges. However, the service life of EAC pavement was still limited and seldom SBDP could serve longer than 15 years. Studies on the SBDP life extension were still needed.

To overcome the problems mentioned above, the concept of the long-life pavement has been adopted. The longlife pavement is a pavement that can last at least more than 40 years without major structural strengthening [10], and it has been used across the world, especially in Europe and the United States [11-13].

According to this concept, this paper proposes a long-life steel bridge deck pavement (LLSBDP) and presents a performance evaluation program for the proposed pavement. First, the concept of the LLSBDP was given and a LLSBDP was proposed. Second, a numerical analysis was conducted to find the requirements of the LLSBDP. Finally, an experimental study was performed to ensure that the proposed material could meet the requirements of the LLSBDP.

\section{Long-Life Steel Bridge Deck Pavement (LLSBDP)}

A long-life pavement is defined as "a well-designed and wellconstructed pavement where the structural elements last indefinitely, provided that the designed maximum individual load and environmental conditions are not exceeded and that appropriate and timely surface maintenance is carried out" [14]. The basic idea of the long-life pavement is to reduce the potential structural distresses by minimizing the tensile strain at the bottom of the AC layer and the compressive strain on top of the subgrade. The normal way of this is to increase the modulus and rigidity of asphalt base layer. In this case, under vehicle loads, all the major pavement distresses can be confined within the surface layer. Only periodical rehabilitation for the surface layer might be needed during the entire design life.

Unlike the ordinary highway asphalt pavement, the SBDP was paved on steel bridge deck, as shown in Figure 1. For the deadweight limitation, the thickness of SBDP was usually $4-8 \mathrm{~mm}$ and usually structured as two layers to get better compact effect. According to the concept of the longlife pavement, a long-life SBDP is expected to have a long-life lower layer without structure distress during service life. Distresses only appeared in the upper layer, which could be recovered by periodical rehabilitation or reconstruction.

The major distresses of the SBDP are cracking and rutting. Rutting is a distress related to the high-temperature performance of the pavement material, and it often occurs in GA or SMA pavements but rarely is seen in EAC pavements. For EAC pavements, cracking is the main distress type, which significantly affects the service life of the SBDP. The existing studies showed that most cracks in SBDP were induced by the tensile stress on the top of the pavement surface, and the cracking developed rapidly from top of the pavement surface to the steel deck for the stress concentration at the cracking tip $[4,15]$. To reduce the risk of the through cracking, it is better to decrease the tensile stress on the top of the pavement surface and select a stronger lower layer material. In this case, based on the basic idea of long-

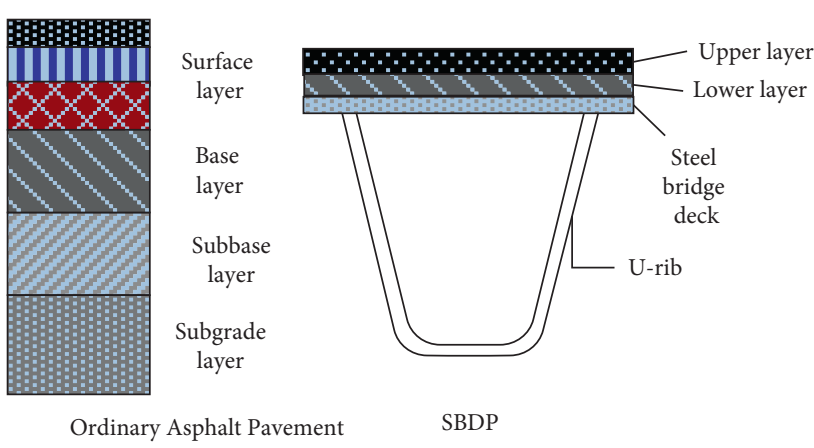

FIGURE 1: Structures of ordinary asphalt pavement and SBDP.

life pavement, the LLSBDP should have the following characters:

(1) LLSBDP should have 2 or more layers: the lower layer performed as base layer, and the upper layer served as wearing course. For LLSBDP, the lower layer should have long life without structural distress, while the upper layer can be rehabilitated periodically.

(2) The tensile stress on the top of the surface pavement should be minimized to avoid the potential cracking. Once cracking appeared, to avoid the cracking directly developed to the base layer, the lower layer should have a larger cracking resistance than the upper layer.

(3) Besides, to provide a good serviceability, the LLSBDP should meet other requirements of the normal SBDP, such as good stabilities and deformation compatibility with steel deck.

The "EAC + EAC" pavement structure shown in Figure 2 is the most used structure of the SBDP. However, it could not meet the LLSBDP requirements listed above. Under comprehensive consideration of LLSBDP and "EAC + EAC" structure, the "EAC+SMA" structure is proposed for LLSBDP. As shown in Figure 3, in the "EAC+SMA" structure, the lower base layer is paved using EAC, while the upper layer material is SMA. EAC have much greater cracking and fatigue resistances than SMA; thus, once cracking occurred, the development of cracking would be stopped at the interface between two layers. A numerical analysis and an experimental program will be conducted below to evaluate the feasibility of this proposed LLSBDP structure.

\section{Numerical Analysis}

As mentioned above, the top-down cracking caused by the tensile stress is the main distress of the SBDP. To avoid the early failure of the SBDP, the tensile stress on the top of the pavement should be considered as the control index. In order to make the stress statuses clear and assess the anticracking performance of proposed LLSBDP structure, a finite-element model of "EAC + SMA" was established and analyzed using the commercial finite-element package ABAQUS. Meanwhile, numerical analysis of the 


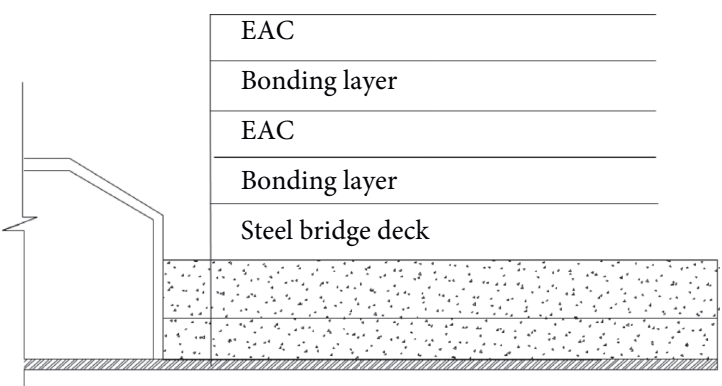

Figure 2: “EAC + EAC” structure.

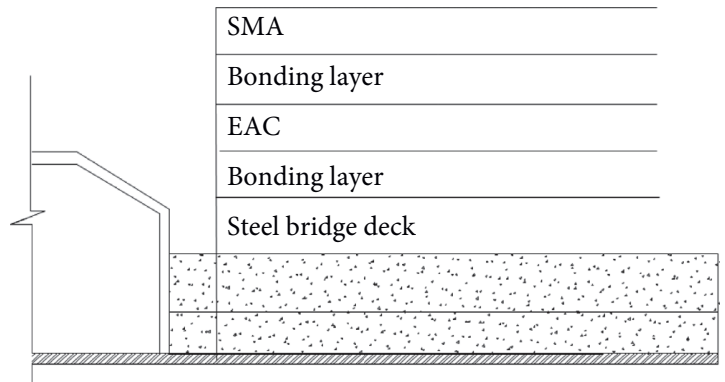

Figure 3: "EAC + SMA" structure.

"EAC + EAC" structure with same parameters was also performed for comparison.

\subsection{Finite-Element Model}

3.1.1. Assumptions. SBDP was bonded with the steel bridge deck and worked together; therefore, when performing the numerical simulation, the SBDP and the steel bridge deck should be considered as a whole structure. The numerical analysis was focused on the tensile stress in the pavement layer; in this case, during the analysis, three assumptions were made as follows:

(1) The SBDP materials were continuous, completely elastic, homogeneous, and isotropic

(2) The relative displacements and deformations of the steel bridge deck were tiny

(3) The interface between the SBDP and the bridge deck is completely continuous

3.1.2. Model. According to the Saint-Venant's principle, the stress states of the pavement were most affected by the load on certain local area. In this case, an orthotropic steel plate with 4 diaphragms and 7 U-rib was modeled to simulate the steel bridge, as shown in Figure 4. In this model, the asphalt pavement was simulated using 8-note solid element, while the steel bridge deck was modeled using the shell element. The pavement and steel deck were tied through the rigid links to ensure that they are deformed together. After meshing, 21,546 elements were used in the FE model. The parameters used in the model are listed in Table 1, where the geometric parameters were adopted from a real bridge in

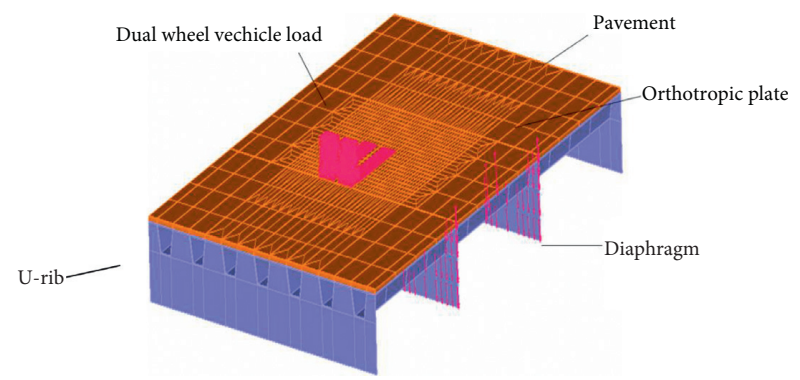

FIGURE 4: Geographic model of the orthotropic steel plate.

TABLE 1: Geometric dimensions and material parameters.

\begin{tabular}{lc}
\hline Item & Parameter \\
\hline Deck thickness $(\mathrm{mm})$ & 14 \\
Diaphragms space $(\mathrm{mm})$ & 2700 \\
Diaphragms thickness $(\mathrm{mm})$ & 14 \\
U-rib thickness $(\mathrm{mm})$ & 8 \\
U-rib space $(\mathrm{mm})$ & 300 \\
U-rib height $(\mathrm{mm})$ & 280 \\
Base layer thickness $(\mathrm{mm})$ & 30 \\
Surface layer thickness $(\mathrm{mm})$ & 30 \\
Poisson ratio of steel plate & 0.25 \\
Elastic modulus of steel plate $(\mathrm{MPa})$ & 210000 \\
Elastic modulus of EAC $\left(-15^{\circ} \mathrm{C}\right)(\mathrm{MPa})$ & 6000 \\
Elastic modulus of EAC $\left(20^{\circ} \mathrm{C}\right)(\mathrm{MPa})$ & 1000 \\
Elastic modulus of EAC $\left(60^{\circ} \mathrm{C}\right)(\mathrm{MPa})$ & 500 \\
Elastic modulus of SMA $\left(-15^{\circ} \mathrm{C}\right)(\mathrm{MPa})$ & 1500 \\
Elastic modulus of SMA $\left(20^{\circ} \mathrm{C}\right)(\mathrm{MPa})$ & 400 \\
Elastic modulus of SMA $\left(60^{\circ} \mathrm{C}\right)(\mathrm{MPa})$ & 200 \\
\hline
\end{tabular}

China. In order to assess the structural performances under different temperatures, $-15^{\circ} \mathrm{C}, 20^{\circ} \mathrm{C}$, and $60^{\circ} \mathrm{C}$ were taken. The moduli of the asphalt concretes under these temperatures were given referring to the Chinese design specifications of asphalt pavement.

3.1.3. Load. The dual wheels load was adopted to simulate the vehicles. Referring to the AASHTO, the rectangular load diagram was used. The tire pressure was set to be $0.91 \mathrm{MPa}$ to simulate the situation of overload 30\%. Considering the structural symmetry, the dual wheels load was initially placed on the top of the diaphragm and then moving longitudinally to the middle of two adjacent diaphragms, as shown in Figure 4. To find the work condition of the structure, 3 load conditions were analyzed, as shown in Figure 5:

Position I: the dual wheel load acted symmetrically on top of a U-rib

Position II: the dual wheel load acted on the middle of two adjacent U-ribs

Position III: the dual wheel load acted on top of the U-rib edge

3.2. Analysis Results. As stated above, the main cause of the cracking, tensile stress on the top of the pavement, was 


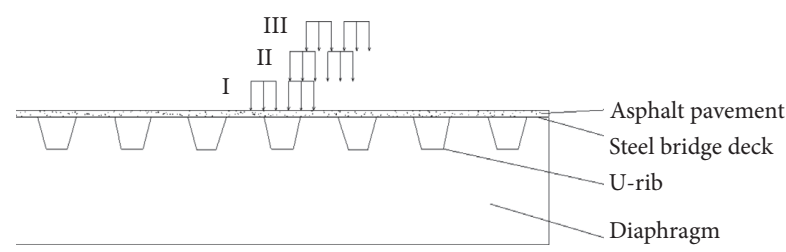

FIgURE 5: Different load positions along the cross section.

chosen as the control index in this numerical analysis. Therefore, based on this, the critical load condition was determined and then the stress status under critical load condition was calculated as follows.

3.2.1. Determination of Critical Load. To determine the critical load position, tensile stresses under 3 different load positions were calculated under $20^{\circ} \mathrm{C}$. During the simulation, the vehicle load was moving in a step of $0.2 \mathrm{~m}$, and the peak values of the tensile stress on the top of the pavement were recorded for every step, as presented in Figure 6. It can be seen clearly that both the transverse tensile stress and the longitudinal tensile stress were greater under load position III. Meanwhile, the largest values of both stresses were appearing when the vehicle load works on the top of the diaphragm.

3.2.2. Critical Stress Status. To simulate the performance of the proposed LLSBDP under different temperatures, the stress status of "EAC + SMA" under critical load was calculated. The responses of the structure "EAC + EAC" under the same conditions were also calibrated for comparison; results are shown in Figure 7.

From Figure 7, it can be seen that the tensile stresses of the pavement are increasing with the temperature decreasing. Meaning that the cracking is easy to appear in low temperatures, the crack resistance of these materials under low temperature should be verified. On the other hand, the tensile stress in "EAC + SMA" structure is obviously smaller than that of "EAC + EAC" structure, meaning that the cracking possibility in the proposed LLSBDP is smaller than the traditional structure. From the result, it can be indicated that, compared to the structure "EAC + EAC," the proposed structure "EAC + SMA" had lower cracking potential.

\section{Experimental Study}

Two series of experiments were involved in this program, material tests and structure tests. In order to ensure that the pavement material can meet the requirement of SBDP, the high-temperature stability and low-temperature crack resistance of EAC and SMA were examined. Particularly, the linear contraction coefficients of EAC were tested to ensure that it can be deformed together with the steel bridge deck. After that, a composite structural specimen was proposed to evaluate the structural performance of the proposed LLSBDP structure.
4.1. Materials. Two asphalt mixtures are involved to the proposed LLSBDP structure, EAC and SMA. The formal one is a mixture of the epoxy asphalt binder and the aggregate, while the latter one is mixed by SBS-modified asphalt and the graded aggregate. The main characters of epoxy asphalt (EA), SBS, and the aggregates were tested and recorded; the detailed information of these materials is presented in $\mathrm{Ta}$ ble 2. The optimum asphalt content of EAC and SMA was determined to $6.3 \%$ and $6.0 \%$, respectively, according to Marshall Mixture procedure. Based on this information, the asphalt concretes were shaped and tested.

4.2. Mixture Test. In this section, to ensure that the pavement material can meet the requirements of LLSBDP, the cracking resistance under different temperatures was tested and compared firstly. Then, the dynamic stability of pavement material was evaluated to ensure their service abilities. At last, the linear contraction of the EAC was tested to ensure that it can work smoothly with the steel bridge deck. The test processes and results were presented in the following.

4.2.1. Indirect Tensile Test. The tensile strength is an important index to evaluate the crack resistance of the paving material. In this test, the general principle in ASTM D486792 was followed and the indirect tensile tests were conducted at both $-15^{\circ} \mathrm{C}$ and $20^{\circ} \mathrm{C}$, corresponding to the normal and low work temperatures of the LLSBDP. The test results are presented in Figure 8.

According to the numerical simulation, the critical tensile stress on the top of the SMA layer at $-15^{\circ} \mathrm{C}$ and $20^{\circ} \mathrm{C}$ was $0.87 \mathrm{MPa}$ and $0.55 \mathrm{MPa}$, respectively. Figure 8 shows that the tensile strength of SMA at $-15^{\circ} \mathrm{C}$ and $20^{\circ} \mathrm{C}$ was $1.58 \mathrm{MPa}$ and $0.77 \mathrm{MPa}$, while the tensile stress values of EAC were $11.17 \mathrm{MPa}$ and $6.33 \mathrm{MPa}$. It can be indicated that both of EAC and SMA could meet the critical tensile stress from numerical simulation. On the other hand, the cracking resistance of the EAC was significantly greater than that of SMA. Once the working stress exceeds the strength of SMA, the cracking may appear in SMA layer; meanwhile, the stress was released together with the cracking. Thus, considering the high cracking resistance of EAC, the cracking is hard to develop to the base EAC layer.

4.2.2. Wheel Tracking Test. The wheel tracking tests were conducted at $60^{\circ} \mathrm{C}$ to evaluate the permanent deformation characteristics of the asphalt mixtures. During the test, the $300 \mathrm{~mm} \times 300 \mathrm{~mm} \times 50 \mathrm{~mm}$ slab specimens were compacted by a rolling compactor. A contact pressure of $700 \mathrm{kPa}$ was applied to the slab specimens, and the wheel passed 42 times per minute at the center of the specimen using the wheel tracking tester. The test results show that the dynamic stability (DS) of EAC and SMA was 12,820 cycles and 4,598 cycles, which were much larger than the required value 3,000 cycles [17]. Both the EAC and SMA have good high-temperature performance. 


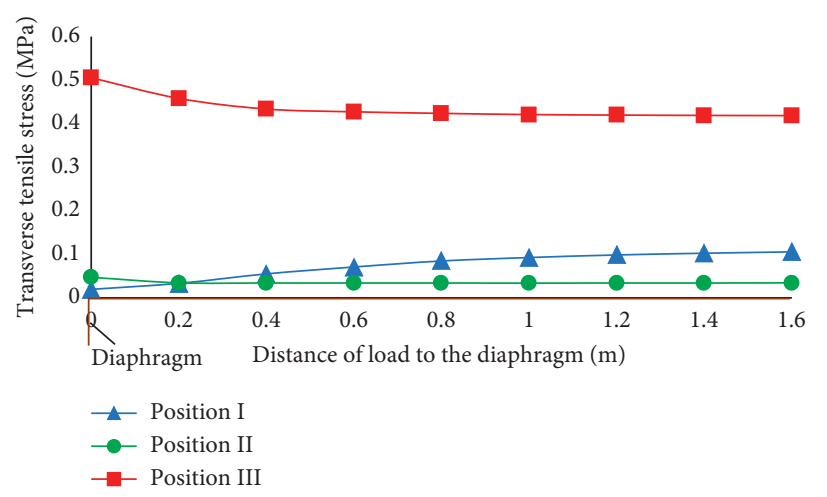

(a)

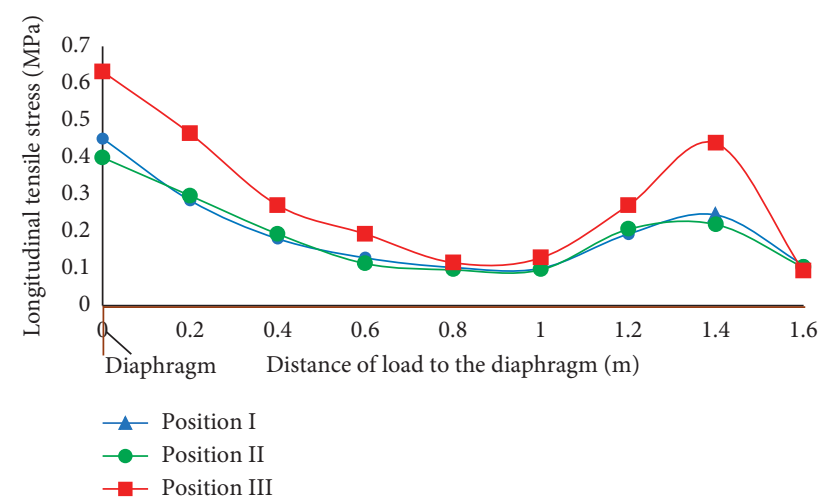

(b)

Figure 6: Tensile stress on the top of the pavement under different load positions. (a) Transverse tensile stress. (b) Longitudinal tensile stress.

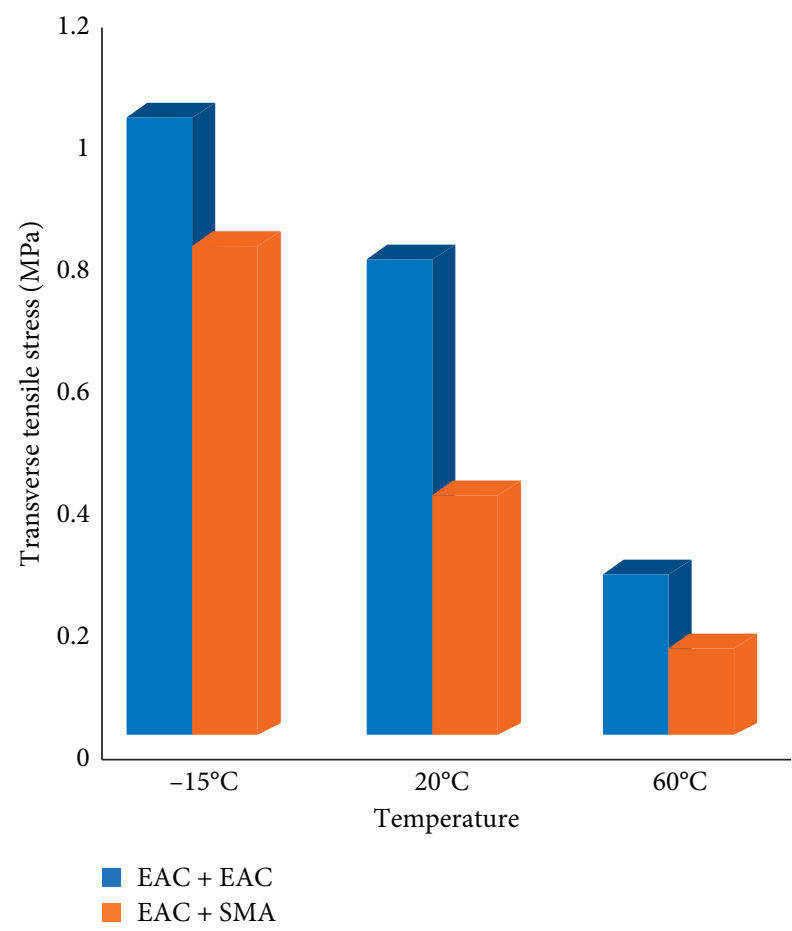

(a)

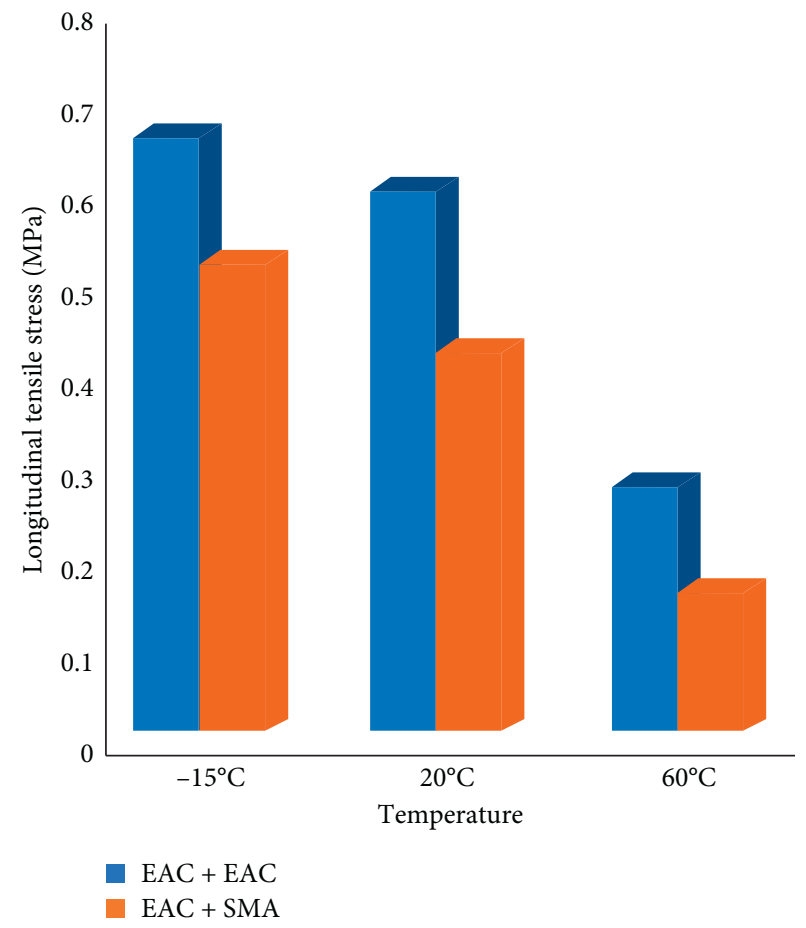

(b)

Figure 7: Tensile stress on the top of the pavement surface under different temperatures. (a) Transverse tensile stress. (b) Longitudinal tensile stress.

TABle 2: Technique indices of EA, SBS, and the aggregate.

\begin{tabular}{lccc}
\hline Materials & Technical indices & Criteria [16] & Measured value \\
\hline \multirow{2}{*}{ EA } & Tension strength $(\mathrm{MPa})$ & $\geq 1.5$ & 3.26 \\
& Elongation at break $(\%)$ & 2200 & 243 \\
& Penetration ratio $\left(25^{\circ} \mathrm{C}, 100 \mathrm{~g}, 5 \mathrm{~s}\right), 0.1 \mathrm{~mm}$ & $\geq 70$ & 68 \\
SBS & Softening point $(\mathrm{R} \& \mathrm{~B})\left({ }^{\circ} \mathrm{C}\right)$ & $\geq 30$ & 85 \\
& Ductility $\left(5^{\circ} \mathrm{C}, 50 \mathrm{~mm} / \mathrm{min}\right)(\mathrm{cm})$ & $\leq 3.00$ & 37 \\
& Brookfield viscosity $\left(135^{\circ} \mathrm{C}\right)(\mathrm{Pa} \cdot \mathrm{s})$ & $\geq 85.0$ & 2.77 \\
& Elastic restitution $\left(25^{\circ} \mathrm{C}, 10 \mathrm{~cm}, 30 \mathrm{~min}\right)(\%)$ & $\leq 22.0$ & 11.5 \\
Aggregate & Wear value $(\%)$ & $\geq 12$ & 85.2 \\
& Crushing value $(\%)$ & $\leq 4$ & 4 \\
& Adhesion level & $\leq 5$ & 0.7 \\
\hline
\end{tabular}




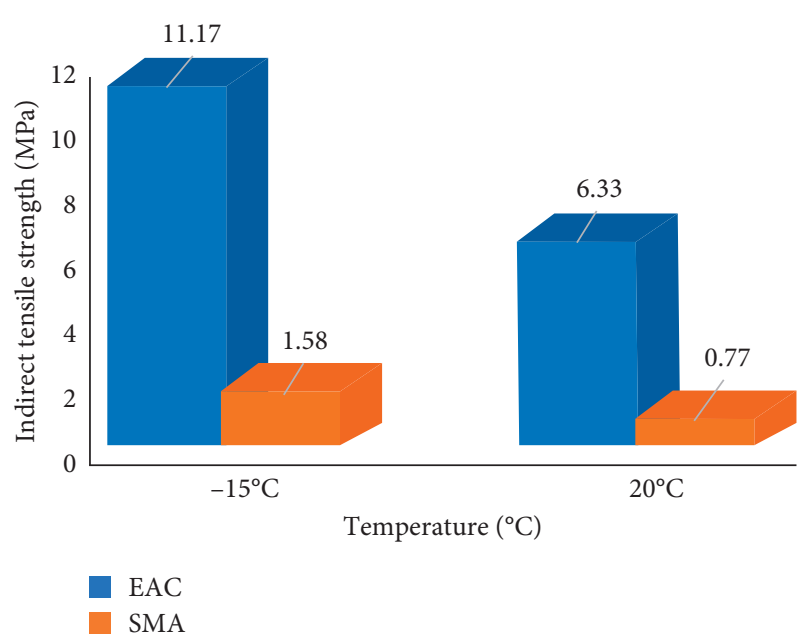

FIgURE 8: The indirect tensile test results of EAC and SMA.

4.2.3. Linear Contraction Coefficient Test. The thermal stress is an important load for the infrastructure. In proposed LLSBDP, EAC was used as base layer material that worked with the steel bridge deck. Therefore, the cooperative deformation under thermal stress between EAC and the steel deck should be evaluated. Different materials usually have different deformations under the same temperature change. The coefficient of linear contraction $\alpha$ is always used to define the thermal performance of the material. For a specimen with length $L$ and temperature change of $\Delta T$, if $\Delta T$ is reasonably small, the change in length, $\Delta L$, is generally proportional to $L$ and $\Delta T$ as [18]

$$
\alpha=\frac{\varepsilon}{\Delta T}=\frac{\Delta L}{L \times \Delta T}
$$

where $\varepsilon$ is the thermal strain of the specimen.

If the linear contraction coefficient of the pavement material is the same as that of the steel deck, then they may deform together under the same temperature change. On the contrary, if they have different coefficients of linear contraction, they may deform differently, leading to an internal stress between the two layers and hence resulting in the thermal cracking in the base layer. Therefore, the base layer material is always required to have the similar linear contraction coefficient with the steel.

In this paper, a linear contraction coefficient test device was developed and the linear contraction coefficient of EAC was tested using the device shown in Figure 9. The test device was put into a temperature chamber, and the $250 \mathrm{~mm}$ $\times 30 \mathrm{~mm} \times 35 \mathrm{~mm}$ EAC beam was placed on a glass plane, fixed by two dial gauges. In the beginning, the temperature chamber was set to $5^{\circ} \mathrm{C}$ and hold for 4 hours. Then after recording the value of the dial gauges, the temperature dropped to the temperatures of $0^{\circ} \mathrm{C},-5^{\circ} \mathrm{C},-10^{\circ} \mathrm{C}$, and $-15^{\circ} \mathrm{C}$, respectively, with all temperatures lasting for 4 hours, and the deformations $\Delta T$ of the specimen were recorded from the dial gauge.

According to the definition of the linear contraction coefficient stated in equation (1), the linear contraction coefficient during every temperature drop can be calculated

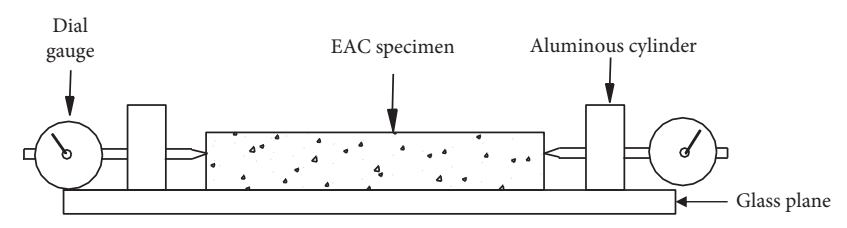

Figure 9: Linear contraction coefficient test of EAC.

as listed in Table 3. As can be seen, the average linear contraction coefficient of EAC is $1.74 \times 10^{-5 \circ} \mathrm{C}^{-1}$, a little larger than that of the steel. Suppose that the temperature drops $50^{\circ} \mathrm{C}$ within a day and the average tensile modulus of EAC is $2000 \mathrm{MPa}$, then according to equation (1), the thermal stress in EAC layer will be

$$
(1.74-1.20) \times 10^{-5^{\circ}} \mathrm{C}^{-1} \times 50^{\circ} \mathrm{C} \times 2000 \mathrm{MPa}=0.54 \mathrm{MPa} \text {. }
$$

Since the tensile strength of EAC is much larger than $0.54 \mathrm{MPa}$ according to the indirect tensile strength test, no thermal cracking will occur in the EAC layer.

4.3. Composite Structure Test. According to the mixture tests, the EAC and SMA were proved to be good material for LLSBDP. However, whether they can work smoothly together or not is still a problem to be verified. Therefore, the structure performance of the proposed LLSBDP is evaluated through a series of composite structure tests. In this section, 10 asphalt mixtures slabs were shaped using the wheelrolling machine, in the order of "EAC base layer + bonder + SMA surface layer." Then, 5 slabs were used for the wheel tracking test and another 5 slabs were cut into $250 \mathrm{~mm} \times 50 \mathrm{~mm} \times 40 \mathrm{~mm}$ beams, for bending test.

4.3.1. Wheel Tracking Test. The wheel tracking tests were conducted at $60^{\circ} \mathrm{C}$ to evaluate the high-temperature performance of "EAC + SMA." The rut slab was formed in the order of "the lower layer, bonding layer, and the upper layer." The test results showed that the average dynamic stability of the "EAC + SMA" structure is 9,500 cycles, smaller than that of EAC, but larger than that of SMA. The combination of EAC and SMA may improve the dynamic stability of SMA, although it was lower than the "EAC+EAC" structure and still much larger than the required value 3000 cycles. It can be indicated that the proposed LLSBDP has good rutting resistance.

4.3.2. Bending Beam Test. To evaluate the strength and deformation characteristics of the structure under low temperature, the bending beam test was conducted using UTM25 at $-10^{\circ} \mathrm{C}$, with a loading rate of $50 \mathrm{~mm} / \mathrm{min}$. The bending beam tests results showed that the maximum bending strength is $14.2 \mathrm{MPa}$ and the maximum bending strain is $2180 \mu \varepsilon$. It is also observed in the tests that the cracking first appeared in the SMA layer and then slowly developed to the interface between SMA and EAC; after a little while, with the load increasing, the cracking develops to the EAC layer and the whole structure fracture suddenly, as shown in Figure 10. 
TABLE 3: The linear contraction coefficient of EAC.

\begin{tabular}{lcccc}
\hline \multirow{2}{*}{ Material type } & \multicolumn{4}{c}{ Coefficient of linear contraction $\left({ }^{\circ} \mathrm{C}^{-1}\right)$} \\
\\
\hline EAC & $5 \sim 0^{\circ} \mathrm{C}$ & $0 \sim-5^{\circ} \mathrm{C}$ & $-5 \sim-10^{\circ} \mathrm{C}$ & $-10 \sim-15^{\circ} \mathrm{C}$ \\
SMA & $2.52 \times 10^{-5}$ & $1.69 \times 10^{-5}$ & $1.46 \times 10^{-5}$ & $1.27 \times 10^{-5}$ \\
Steel & $3.45 \times 10^{-5}$ & $3.48 \times 10^{-5}$ & $2.27 \times 10^{-5}$ & $2.16 \times 10^{-5}$ \\
\hline
\end{tabular}

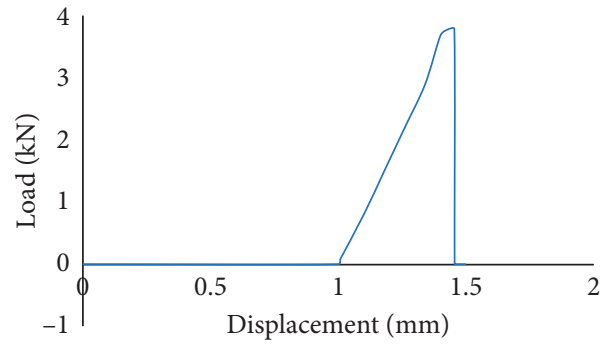

(a)

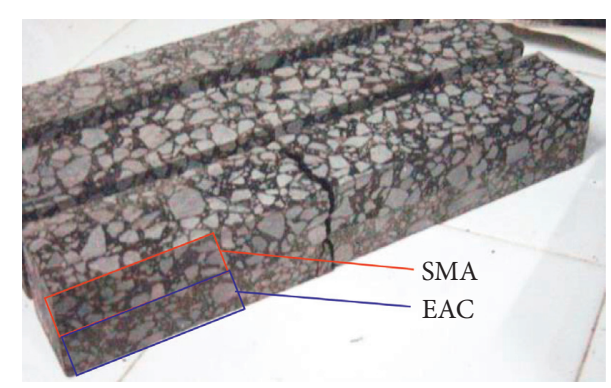

(b)

Figure 10: The bending beam tests results of the composite structure. (a) Load-displacement curve. (b) Experimental specimens.

The fracture process observed in the test implied that the distresses of the proposed "EAC+SMA" structure first occurred in the SMA layer; if the upper layer can be rehabilitated or reconstructed periodically, the base EAC layer can last for a long life.

\section{Case Study}

The Combash Bridge is an $800 \mathrm{~m}$-long steel bridge across the Ulan Mulun River in Inner Mongolia Province of China. It is the biggest landscape bridge in Asia. The bridge is a double tower double cable stayed bridge, with a main span of $450 \mathrm{~m}$. The average temperature of Combash District is $1^{\circ} \mathrm{C}-15^{\circ} \mathrm{C}$, while the average low and high temperatures are $-18^{\circ} \mathrm{C}$ and $36^{\circ} \mathrm{C}$.

For the pavement structure of the Combash Bridge, "EAC + EAC" was firstly selected, considering that EAC was easy to crack in low temperature and the cost of the construction. "EAC + SMA" was finally chosen after a comparison study. The Combash Bridge was completed and open on 10/23/2012 using "EAC+SMA" structure. After using for nearly 8 years, the SMA surface layer is still maintained in good condition and no structural distress has been found in EAC base layer.

Besides, the "EAC + SMA" structure was used on many other steel bridges for its good performance and life, for example, the Shishou Bridge and Jiayu Bridge across the Yangtze River in Hubei Province. The SBDP of these 2 bridges are maintained in good condition without early distress after using for nearly 1 year.

\section{Discussion and Conclusion}

Referring to the concept of LLAP, this paper puts forward the requirements of the LLSBDP. The "EAC + SMA" was proposed for LLSBDP; then a numerical analysis and an experimental program were conducted to evaluate the performance of the proposed structure. The conclusions were drawn as follows.

First, according to the requirements of LLSBDP, the lower layer should have a larger cracking resistance than the upper layer. The indirect tensile test results showed that the cracking resistance of EAC is remarkably greater than SMA, implying that the cracking in the SMA layer is hard to develop to the EAC layer. This was also improved from the composite structure test. On the other hand, compared to EAC, SMA has smaller elastic modulus and larger plasticity, and this will decrease the tensile stress on the top of the pavement and slow down the cracking developing velocity in the SMA layer. In this case, given periodical rehabilitation or reconstruction to the SMA layer, the EAC layer can work for a long life without structural distress. The first requirement of LLSBDP can be qualified.

Second, the numerical analysis results show that the tensile stress on the top of the "EAC + SMA" structure was significantly smaller than the traditional "EAC $+E A C$ " structure, and the cracking resistances of both the SMA and the EAC could meet the working stress. Therefore, the second requirement of LLSBDP can be qualified.

Third, the mixture test and the composite structure test results showed that the pavement material had good stabilities and deformation compatibility with steel deck; the structure can work smoothly with each other and the steel deck, meaning that the second requirement of LLSBDP can be qualified.

The results showed that the proposed structure can meet the requirements of the LLSBDP. Besides the study in the paper, SMA had better skid resistance and lower economic cost and also is easy to be rehabilitated compared to EAC. This will be done in further research and paper.

\section{Data Availability}

The data used to support the findings of this study are included within the article. 


\section{Conflicts of Interest}

The authors declare that they have no conflicts of interest.

\section{Acknowledgments}

The authors would like to graciously acknowledge the National Key Research and Development Project of China, under Grant nos. 2018 YFB1600300 and 2018 YFB1600304.

\section{References}

[1] W. Huang, Z. D. Qian, G. Chen, and J. Yang, "Epoxy asphalt concrete paving on the deck of long-span steel bridges," Chinese Science Bulletin, vol. 48, no. 21, pp. 2391-2394, 2003.

[2] T. Nishizawa, K. Himeno, K. Nomura, and K. Uchida, "Development of a new structural model with prism and strip elements for pavements on steel bridge decks," International Journal of Geomechanics, vol. 1, no. 3, pp. 351-369, 2001.

[3] Z. X. Li, T. Q. Zhou, T. H. T. Chan, and Y. Yu, "Multi-scale numerical analysis on dynamic response and local damage in long-span bridges," Engineering Structures, vol. 29, no. 7, pp. 1507-1524, 2007.

[4] L. Chen, Z. Qian, and J. Wang, "Multiscale numerical modeling of steel bridge deck pavements considering vehiclepavement interaction," International Journal of Geomechanics, vol. 16, no. 1, Article ID B4015002, 2016.

[5] H. M. Park, J. Y. Choi, H. J. Lee, and E. Y. Hwang, "Performance evaluation of a high durability asphalt binder and a high durability asphalt mixture for bridge deck pavements," Construction and Building Materials, vol. 23, no. 1, pp. 219225, 2009.

[6] Y. K. Cheng and Z. W. Shi, "Experimental study on nano-SiO improving concrete durability of bridge deck pavement in cold regions," Advances in Civil Engineering, vol. 2019, Article ID 5284913, 9 pages, 2019.

[7] Z. Qian, L. Chen, C. Jiang, and S. Luo, "Performance evaluation of a lightweight epoxy asphalt mixture for bascule bridge pavements," Construction and Building Materials, vol. 25, no. 7, pp. 3117-3122, 2011.

[8] T. W. Kim, J. Baek, H. J. Lee, and S. Y. Lee, "Effect of pavement design parameters on the behaviour of orthotropic steel bridge deck pavements under traffic loading," International Journal of Pavement Engineering, vol. 15, no. 5, pp. 471-482, 2014.

[9] Z. Wang and S. Zhang, "Fatigue endurance limit of epoxy asphalt concrete pavement on the deck of long-span steel bridge," International Journal of Pavement Research and Technology, vol. 11, no. 4, pp. 408-415, 2018.

[10] H. J. Lee, J. H. Lee, and H. M. Park, "Performance evaluation of high modulus asphalt mixtures for long life asphalt pavements," Construction and Building Materials, vol. 21, no. 5, pp. 1079-1087, 2007.

[11] B. Ferne, "Long-life pavements-a European study by ELLPAG," International Journal of Pavement Engineering, vol. 7, no. 2, pp. 91-100, 2006.

[12] D. Merrill, A. Van Dommelen, and L. Gáspár, "A review of practical experience throughout Europe on deterioration in fully-flexible and semi-rigid long-life pavements," International Journal of Pavement Engineering, vol. 7, no. 2, pp. 101-109, 2006.

[13] D. E. Newcomb, M. Buncher, and I. J. Huddleston, "Concepts of perpetual pavements," in Transportation Research Circular No. 503. Perpetual Bituminous Pavements, pp. 4-11, Transportation Research Board, Washington, DC, USA, 2000.
[14] FEHRL, ELLPAG Phase 2 Report: A Guide to the Use of LongLife Semi-Rigid Pavements, Forum of European National Highway Research Laboratories (FEHRL), Brussels, Belgium, 2009.

[15] L. Chen, Z. Qian, and Q. Lu, "Crack initiation and propagation in epoxy asphalt concrete in the three-point bending test," Road Materials and Pavement Design, vol. 15, no. 3, pp. 507-520, 2014.

[16] Ministry of Transport of People's Republic of China, Specifications for Design and Construction of Pavement on Highway Steel Bridge (JTG/T3364-02-2019), People's Communication Press, Beijing, China, 2019.

[17] B. Yao, C. Chen, and J. L. Kenneth, "Performance characteristics of diluted epoxy asphalt binders and their potential application in chip seal," Journal of Materials in Civil Engineering, vol. 31, no. 12, Article ID 04019290, 2019.

[18] T. A. Kompan, S. V. Kondrat'ev, A. S. Korenev et al., "Extending the temperature range of the national primary standard for the unit of the thermal linear expansion coefficient," Measurement Techniques, vol. 58, no. 12, pp. 1341-1346, 2016. 